\title{
Age, Gender and Mechanism of Injury Interactions in Post-Concussion Syndrome
}

\author{
Brenda Varriano, George Tomlinson, Apameh Tarazi, Richard Wennberg, \\ Charles Tator, Maria Carmela Tartaglia
}

\begin{abstract}
Background: Certain factors such as age and gender seem to affect the risk of developing post-concussion syndrome (PCS). We assessed the interactions between age, gender, concussion history and mechanism of injury in PCS patients so that a better understanding could guide the development of targeted prevention strategies. Methods: Demographic data including age, gender, concussion mechanism of injury and concussion history were collected from (1) a prospective study evaluating PCS biomarkers and (2) a retrospective chart review of PCS patients. A total of 437 PCS patients who were assessed at the Canadian Concussion Centre or Toronto Western Hospital, Toronto, ON, were included. Results: Overall, there were more men with PCS; however, a greater percentage of women had PCS after a single concussion. The results showed that age, gender and concussion history are conditionally dependent on the mechanism of injury, and independent of one another. The relative frequency of having PCS was greater in the following instances: (1) being a woman and having had concussion from a fall or motor vehicle collision (MVC), (2) being older and having had concussion from a fall or MVC or (3) having a single concussion with cause being MVC or fall. Conclusion: In patients with PCS, age and gender interact with the mechanism of injury to influence the risk of concussion. Targeted prevention strategies may be essential to prevent injuries leading to PCS.
\end{abstract}

RÉSUMÉ: Relations entre l'âge, le sexe et les mécanismes d'une lésion cérébrale dans le cas du syndrome post-commotionnel. Contexte: Certains facteurs, par exemple l'âge et le sexe, semblent avoir une incidence sur le risque d'être atteint du syndrome post-commotionnel (SPC). Afin de mieux comprendre cet ensemble de symptômes et d'orienter les efforts visant à développer des stratégies de prévention ciblées, nous avons donc tenté d'évaluer, chez des patients atteints du SPC, les relations entre l'âge, le sexe, des antécédents de commotions cérébrales et les mécanismes ayant causé une lésion cérébrale. Méthodes: Des données portant sur l'âge, le sexe, les mécanismes d'une lésion cérébrale et des antécédents de commotion cérébrale ont été collectées à partir de deux sources: (1) une étude prospective évaluant les marqueurs du SPC; (2) un examen rétrospectif des dossiers de patients atteints du SPC. Au total, 437 patients de ce type ayant été évalués au Canadian Concussion Centre ou au Toronto Western Hospital (Ontario) ont été inclus dans cette étude. Résultats: Dans l'ensemble, on a recensé plus d'hommes atteints du SPC. Cela dit, un pourcentage plus élevé de femmes ont présenté un tel syndrome à la suite d'une seule commotion cérébrale. Nos résultats ont également montré que certains des facteurs mentionnés ci-dessus (l'âge, le sexe ainsi que des antécédents de commotion cérébrale) sont tributaires des mécanismes d'une lésion cérébrale et indépendants les uns des autres. Ainsi, la fréquence relative de cas de SPC était plus élevée au regard des situations suivantes: (1) être de sexe féminin et avoir subi une commotion cérébrale à la suite d'une chute ou d'un accident automobile; (2) être plus âgé et avoir subi une commotion cérébrale à la suite d'une chute ou d'un accident automobile; (3) avoir subi une seule commotion cérébrale pouvant être attribuée à un accident automobile ou à une chute. Conclusions: Couplés aux mécanismes d'une lésion cérébrale dans le cas de patients atteints du SPC, tant l'âge que le sexe sont susceptibles d'avoir une incidence sur le risque de subir une commotion cérébrale. Il se pourrait donc que des stratégies de prévention davantage ciblées soient essentielles afin de prévenir les lésions entraînant un SPC.

Keywords: Post-concussion syndrome, Gender, Age, Mechanism of Injury

doi:10.1017/cjn.2018.322

Can J Neurol Sci. 2018; 45: 636-642

Concussion, also known as mild traumatic brain injury (mTBI), is becoming a growing concern. A concussion is a complex process induced by a biomechanical force that affects the brain. ${ }^{1}$ Approximately 100-300/100,000 individuals are treated for concussion at a hospital annually, which underestimates the true incidence of concussion as many do not seek medical care. ${ }^{2}$

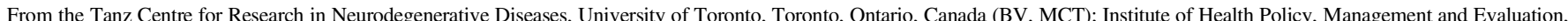

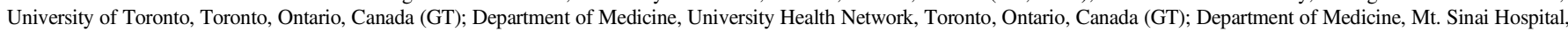

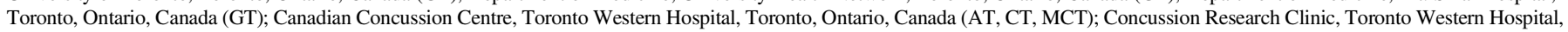

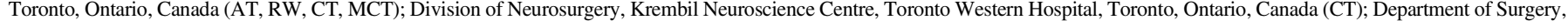
University of Toronto, Toronto, Ontario, Canada (CT); Division of Neurology, Krembil Neuroscience Centre, Toronto Western Hospital, Toronto, Ontario, Canada (RW, MCT).

Presented at the Concussion in Women and Girls Symposium, Oral Presentation, Saturday, September 23, 2017, Toronto, ON, Canada.

Received January 16, 2018. Final Revisions Submitted May 26, 2018. Date of Acceptance June 24, 2108.

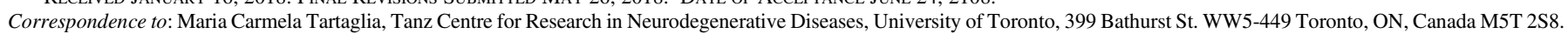
Email: carmela.tartaglia@uhn.ca 
Most people (85\%-90\%) recover from concussion within 7-10 days after the injury, but the symptoms can persist for months, years or indefinitely leading to a condition referred to as postconcussion syndrome (PCS). ${ }^{3-6}$ Although there is debate over the definition of PCS, the Diagnostic and Statistical Manual of Mental Disorders (DSM-IV) is one of the more common criteria, along with the International Statistical Classification of Diseases and Related Health Problems (ICD-10), and includes the following: ${ }^{1}$ a history of head trauma that has caused concussion, ${ }^{2}$ evidence of poor performance on neuropsychological assessment of attention or memory $a^{3}$ three or more of the following symptoms occurring after head trauma and lasting at least three months: mood changes, fatigue, difficulty sleeping, change in personality and apathy and a significant decline in social or occupational functioning resulting from injury. ${ }^{7-9}$

There is increasing evidence that certain populations are at greater risk of developing PCS, including the elderly, the very young, women and those with a learning disability. ${ }^{10-17}$ Concussion can result from a wide variety of mechanisms including sports, motor vehicle accidents, falls and trauma. The relationship between development of PCS and mechanism of concussion is not known. There is some evidence that there are gender differences in the incidence of PCS from sports. ${ }^{18} \mathrm{~A}$ recent narrative review by Brook et $\mathrm{al}^{19}$ found that women showed the greatest acute neurological complications after concussions, including slower reaction times, increased symptoms, worse memory function and greater recovery time, compared with men. The longer recovery time in women may also increase the risk of experiencing a second concussion before symptoms have fully resolved, thus increasing the risk for developing PCS. ${ }^{20}$ Most research focuses on athletes, but a few have evaluated gender differences in the non-athletic community and also found that women are at a higher risk of concussion and go on to develop PCS. ${ }^{12,17}$ More recently, some research is beginning to address gender differences in assault, where $68 \%$ of women experiencing intimate partner-related injury have experienced at least one mTBI and $44 \%$ have experienced multiple mTBIs. ${ }^{21,22}$

Age also appears to influence the prevalence of PCS. The elderly appear to have a higher risk of developing PCS and have a higher likelihood of never recovering. ${ }^{12,17}$ In some studies, mTBI has been related to higher mortality in the elderly after correcting for factors such as patient demographics and dementia diagnosis. ${ }^{23}$ In addition, falls are a growing concern among the elderly, which puts them at greater risk for concussion and potentially $\mathrm{PCS}^{24}$ There is also growing concern for PCS in pediatric athletes, and the rate of sport-related concussion has been increasing significantly in this population. ${ }^{25}$ A recent study on patients visiting a PCS clinic revealed that over half of the patients with sport-related PCS were under the age of $18 .^{5}$ This study had reported a higher than usual incidence of youth PCS cases, defined as 18 years of age or younger, owing to inclusion of clinic patients ranging from the ages of 11 and older, rather than simply adult professional athletes alone. ${ }^{5}$

Age and gender influence the risk of developing PCS. ${ }^{12,17}$ Although there is some emerging evidence that there is a relationship between the mechanism of concussion injury and age or gender, the nature of that interaction is largely unknown. As treatment for PCS is not well developed, there is a need for effective, targeted concussion prevention strategies and monitoring of high-risk patients following an mTBI. ${ }^{26}$ Multiple factors contribute to the risk of developing PCS from concussion, and a better understanding of these interactions is important when developing strategies to aid in prevention. Therefore, our study sought to better understand the interaction among variables such as age, gender, mechanism of injury and concussion history in patients with PCS so as to assist in the development of targeted prevention strategies and more effective allocation of resources.

\section{Materials ANd Methods}

\section{Subjects}

Patients with PCS were included from two sources: ${ }^{1}$ a prospective biomarker PCS study that had completed enrollment (recruited from the Canadian Concussion Centre), and ${ }^{2}$ from clinical charts of patients who presented to the University Health Network Concussion Clinic from January 2010 to April 2016 for assessment of persistent symptoms after a concussion. All participants (prospective biomarker and clinical charts) included in this study completed a neurological examination, neuropsychological assessment and neuroimaging. Patients identified in clinical charts were referred by one of the following methods: a primary care provider or a specialist including neurologists and psychiatrists. Canadian Concussion Centre research participants were originally recruited for research purposes. There was no overlap between these two sources. Modified DSM criteria were used in this study: all patients had three or more symptoms for at least 3 months; disturbance caused significant impairment in social or occupational functioning; and significant decline from a previous level of functioning.

Inclusion criteria (prospective biomarker PCS study and retrospective data) were as follows: patients diagnosed with PCS using modified DSM-IV criteria (see above), with documented mechanism of injury and age of index concussion. ${ }^{8}$ History of concussions was determined by the patient's ability to recall injuries caused by a blow to the head or body. There were no restrictions for inclusion of PCS cases based on the number of previous concussions. Patients seen in this adult PCS clinic had to have been a teenager or older. No pediatric cases were included in this study. Patients seen in this adult PCS clinic were between 17 and 81 years of age.

Exclusion criteria included the inability to recall the cause of the index concussion, a history of neurological or developmental disorder, psychiatric illness or other illness affecting the brain.

The Research Ethics Board of the University Health Network (UHN) approved both studies (retrospective and prospective biomarker). Consent was obtained from all participants in the biomarker study, as outlined by the UHN research protocol. Ethics approval was obtained for the retrospective data collection from clinical charts.

\section{Variables Analyzed}

The following data were obtained from the prospective PCS study and retrospective chart review: gender, age, number of concussions, duration of PCS symptoms and mechanism of injury of concussion that led to PCS. Patients were divided into two age groups, 49 or less and 50 or more, in keeping with recent studies of age-related outcomes following an mTBI. ${ }^{27,28}$ Cause of concussion was divided into five groups: falls, motor vehicle collision (MVC), sport, assault and not otherwise specified (NOS). NOS 
included any accident one may experience at work or during daily activities resulting in concussion such as bumping one's head.

\section{Statistical Analysis}

Population demographics were described using proportions and frequencies. $\chi^{2}$ tests were used to compare the distribution of the mechanism of injury between genders and between age groups.

A log-linear model was used to describe the full set of relationships among age, gender, mechanism of injury and concussion history. The full (all-interactions) model included ${ }^{1}$ age, gender, mechanism of injury or $^{2}$ age, gender, mechanism of injury and concussion history. Simpler subsets of the model that dropped certain two-, three- or four-way interactions, and that compared the fit of the simpler models with the full model, were examined. The final model was the simplest model that was not statistically significantly different from the full model. Estimated odds ratios (OR) were calculated to summarize the relationships between the related variables in the model. All analyses were performed using SPSS Statistics Software (version 23.0), R (version 3.4.0) and Microsoft Excel (2016). ${ }^{24}$

\section{ReSUlts}

\section{Patient Population}

A total of 437 PCS cases were included for analysis (Table 1). Of those 437 cases, 118 (27.0\%) PCS cases were identified retrospectively from clinic charts, whereas the latter $319(73 \%)$ cases were identified from a prospective biomarker study on PCS. The PCS patient group comprised more men $(251 ; 57.2 \%)$ than women $(186 ; 42.6 \%)$. There were more younger ( $\leq 49$ years) $(354$; $81.0 \%)$ than old $(>50$ years) $(83 ; 19.0 \%)$ PCS patients. Overall, $96(22.0 \%)$ patients had PCS after a single concussion, whereas $341(78.0 \%)$ had a history of multiple concussions. A greater proportion of women $(29.0 \%)$ had PCS after a single concussion compared with men (16.7\%), respectively (Table 2). A greater proportion of older patients $(43.9 \%)$ had PCS after a single concussion compared with younger patients $(17.0 \%)$, respectively (Table 2).

\section{$\chi^{2}$ Analysis}

There were many significant two-way interactions between variables described in analyses 1-6. These interactions showed significant differences between groups within the different mechanisms of concussion. Non-significant differences between groups within concussion mechanism were not included in the analysis summary. Percentages and proportions are shown in Table 1.

\section{Analysis 1: Gender and Mechanism of Injury}

There was a significant relationship between gender and the mechanism of injury in PCS patients $(p<0.01)$. There were a greater proportion of women with concussions from falls and $\mathrm{MVC}$, and men with concussion from sport.

\section{Analysis 2: Age and Mechanism of Injury}

There was a significant relationship between age and mechanism of injury in PCS patients $(p<0.01)$. There were a greater proportion of older patients with concussion from falls and $\mathrm{MVC}$, and younger patients with concussion from sport.

Table 2: Concussion demographics for post-concussion syndrome patients with a single concussion

\begin{tabular}{l|c}
\hline & Single \\
\hline Men & $42(16.9 \%)$ \\
\hline Women & $54(29.0 \%)$ \\
\hline Young & $60(16.9 \%)$ \\
\hline Old & $36(43.3 \%)$ \\
\hline Sport & $16(7.2 \%)$ \\
\hline Fall & $26(40.6 \%)$ \\
\hline MVC & $37(46.2 \%)$ \\
\hline Other (assault + NOS) & $17(23.6 \%)$ \\
\hline
\end{tabular}

$\mathrm{MVC}=$ motor vehicle collision; $\mathrm{NOS}=$ not otherwise specified.

Table 1: Demographics of patients with post-concussion syndrome

\begin{tabular}{|c|c|c|c|c|c|c|}
\hline \multirow[b]{2}{*}{ Variables } & \multicolumn{3}{|c|}{ Women $(n=186)$} & \multicolumn{3}{|c|}{$\operatorname{Men}(n=251)$} \\
\hline & $<50$ years & $50+$ years & Total & $<50$ years & $50+$ years & Total \\
\hline Total cases $(n[\%])^{*}, \#$ & $143(76.9 \%)$ & $43(23.1 \%)$ & $186(100 \%)$ & $211(84.1 \%)$ & $40(15.9 \%)$ & $251(100 \%)$ \\
\hline \multicolumn{7}{|c|}{ Mechanism of injury ( $n[\%])$} \\
\hline Sport $(n[\%])^{*}, \#$ & $65(45.5 \%)$ & $3(7.0 \%)$ & $68(36.6 \%)$ & $140(66.4 \%)$ & $1332.5 \%)$ & $153(61.0 \%)$ \\
\hline $\operatorname{MVC}(n[\%]) *, \#$ & $33(23.1 \%)$ & $14(32.6 \%)$ & $47(25.3 \%)$ & $21(10.0 \%)$ & $12(30.0 \%)$ & $33(13.1 \%)$ \\
\hline Fall $(n[\%])^{*}, \#$ & $22(15.4 \%)$ & $20(46.5 \%)$ & $42(22.6 \%)$ & $13(6.2 \%)$ & $9(22.5 \%)$ & $22(8.8 \%)$ \\
\hline Trauma $(n[\%])$ & $8(5.6 \%)$ & $2(4.7 \%)$ & $10(5.4 \%)$ & $16(7.6 \%)$ & $1(2.5 \%)$ & $17(6.8 \%)$ \\
\hline $\operatorname{NOS}(n[\%])$ & $15(10.5 \%)$ & $4(9.3 \%)$ & $19(10.2 \%)$ & $21(10.0 \%)$ & $5(12.5 \%)$ & $26(10.4 \%)$ \\
\hline Total & $143(100 \%)$ & $43(100 \%)$ & $186(100 \%)$ & $211(100 \%)$ & $40(100 \%)$ & $251(100 \%)$ \\
\hline
\end{tabular}

$\mathrm{MVC}=$ motor vehicle collision; NOS $=$ not otherwise specified.

$p$-values $<0.05$ are considered statistically significant and will be indicated by a single asterisk $(*)$ if there is a significant result between genders (men vs. women).

$p$-values $<0.05$ are considered statistically significant and will be indicated by the hashtag (\#) if there is a significant result between age groups (young $[<50$ years) vs. old $[50+$ years $]]$ in the total population (men and women). 
Analysis 3: Age and Mechanism of Injury in Women

There was a significant relationship between age and mechanism of injury in women with PCS $(p<0.01)$. There were a greater proportion of older women with concussions from falls and younger women with concussion from sport.

\section{Analysis 4: Age and Mechanism of Injury in Men}

There was a significant relationship between age and mechanism of injury in men with PCS $(p<0.01)$. There were a greater proportion of older men with concussion from falls and $\mathrm{MVC}$, and younger men with concussion from sport.

\section{Analysis 5: Gender and Mechanism of Injury in Young Patients}

There was a significant relationship between gender and mechanism of injury in young patients with PCS $(p<0.01)$. There were a greater proportion of younger women with concussion from falls and MVC, and younger men with concussion from sport.

\section{Analysis 6: Gender and Mechanism of Injury in Old Patients}

There was a significant relationship between gender and mechanism of injury in older men and women with PCS $(p<0.01)$; however, post-hoc analysis revealed only trends.

\section{Log-Linear Modeling}

\section{Conditional Independence of Age and Gender Given Mechanism}

Most of the log-linear models contained significant two-way interactions of at least one of the demographic variables and mechanism of injury, as stated in Analyses 1 and 2.

\section{Analysis 1: Analysis of Age, Gender and Mechanism of Injury \\ The simplest model with a good fit to describe the data is the conditional independence model wherein there was a significant relationship between mechanism of injury and age $(p<0.001)$ and mechanism of injury and gender $(p<0.001)$. As NOS and assault had a very low number of cases, in addition to a similar distribu- tion of age and gender, they were combined to create a single group termed "other." The relationship between age and gender in patients with PCS disappears once the mechanism of injury is known. \\ Analysis 2: Analysis of Age, Gender, Mechanism of Injury and Concussion History}

When concussion history is included as a fourth variable in the log-linear model, the simplest good-fitting model is also conditional independence, where there is a significant relationship between mechanism of injury and age $(p<0.01)$, mechanism of injury and gender $(p<0.01)$ and mechanism of injury and concussion history $(p<0.01)$. The relationship between age, gender and concussion history in patients with PCS disappears once the mechanism of injury is known.

\section{Odds Ratio}

There are interactions between gender and mechanism of injury in those having PCS, which are independent of age. The relative frequency of women having PCS if the mechanism of injury is a fall is greater than the frequency of those being a male and having PCS from a sport $(\mathrm{OR}=4.24 ; 95 \%$ confidence interval [CI]: 2.38-7.75), MVC (OR = 1.33; 95\% CI: 0.68-2.63) or "other" $(\mathrm{OR}=2.86$; $95 \% \mathrm{CI}: 1.41-5.56)$, as shown in Table $3(p<0.001)$. There was also a greater relative frequency of women having PCS if the mechanism of injury was an MVC than men having PCS from a sport or cause of injury being other $(p<0.001)$.

There are interactions between age and mechanism of injury in those having PCS, which are independent of gender. There was a greater relative frequency of older patients with PCS with concussion from fall compared with younger PCS patients with concussion from a sport injury $(\mathrm{OR}=11.11$; 95\% CI: 5.56-25.0), MVC $(\mathrm{OR}=1.72$; $95 \%$ CI: $0.87-3.45)$ or "other" $(\mathrm{OR}=4.17$; 95\% CI:1.89-9.09), respectively $(p<0.001)$. All values are shown in Table 4. Similarly, there was greater relative frequency of being older and having PCS if the mechanism of injury was from an MVC than if being younger and having concussion from sport or other $(p<0.001)$.

Finally, there are interactions between concussion history and mechanism of injury in those having PCS, which are independent of age or gender. There was a greater relative frequency of having PCS after a single concussion if the mechanism of injury was from an MVC rather than if the mechanism of injury was sport $(\mathrm{OR}=$ 10.92; 95\% CI: 5.67-21.9), fall $(\mathrm{OR}=1.25$; 95\% CI: $0.65-2.44)$ or "other" $(\mathrm{OR}=2.78 ; 95 \% \mathrm{CI}$ : $1.38-5.60)$, as shown in Table 5

Table 3: Odds ratios for being a woman with post-concussion syndrome, compared with male patients

\begin{tabular}{l|c|c|c}
\hline & Risk & $\mathbf{9 5 \%}$ CI & $p$-Value \\
\hline Fall vs. sport & 4.24 & $2.38-7.75$ & $<0.001^{*}$ \\
\hline Fall vs. MVC & 1.33 & $0.68-2.63$ & \\
\hline Fall vs. other & 2.86 & $1.41-5.56$ & \\
\hline MVC vs. sport & 3.16 & $1.87-5.41$ & $<0.001 *$ \\
\hline MVC vs. other & 2.13 & $1.10-4.00$ & \\
\hline Other vs. sport & 1.50 & $0.85-2.59$ & 0.15 \\
\hline
\end{tabular}

$\mathrm{CI}=$ confidence interval $\mathrm{MVC}=$ motor vehicle collision .

$p$-values $<0.008$ are considered statistically significant after correcting for multiple comparisons and will be indicated by an asterisk (*).

Table 4: Odds ratios for being a young patient with post-concussion syndrome, compared with an older patient

\begin{tabular}{l|c|c|c}
\hline & Risk & $\mathbf{9 5 \%}$ CI & $p$-Value \\
\hline Fall vs. sport & 11.11 & $5.56-25.0$ & $<0.001^{*}$ \\
\hline Fall vs. MVC & 1.72 & $0.87-3.45$ & \\
\hline Fall vs. other & 4.17 & $1.89-9.09$ & \\
\hline MVC vs. sport & 6.67 & $3.26-12.5$ & $<0.001^{*}$ \\
\hline MVC vs. other & 2.38 & $1.11-5.26$ & \\
\hline Other vs. sport & 2.70 & $1.19-6.25$ & 0.015 \\
\hline
\end{tabular}

$\mathrm{CI}=$ confidence interval $\mathrm{MVC}=$ motor vehicle collision

$p$-values $<0.008$ are considered statistically significant after correcting for multiple comparisons and will be indicated by an asterisk $(*)$. 
Table 5: Odds ratios for having post-concussion syndrome after a single concussion, compared with multiple concussions

\begin{tabular}{l|c|c|c}
\hline & Risk & $\mathbf{9 5 \%} \mathbf{C I}$ & $\boldsymbol{p}$-Value \\
\hline MVC vs. sport & 10.92 & $5.67-21.9$ & $<0.001^{*}$ \\
\hline MVC vs. fall & 1.25 & $0.65-2.44$ & \\
\hline MVC vs. other & 2.78 & $1.38-5.60$ & \\
\hline Fall vs. sport & 8.68 & $4.31-18.0$ & $<0.001^{*}$ \\
\hline Fall vs. other & 2.21 & $1.06-4.63$ & \\
\hline Other vs. sport & 3.92 & $1.86-8.33$ & $<0.001^{*}$ \\
\hline
\end{tabular}

$\mathrm{CI}=$ confidence interval MVC $=$ motor vehicle collision .

$p$-values $<0.008$ are considered statistically significant after correcting for multiple comparisons and will be indicated by an asterisk (*).

$(p<0.001)$. Sport was least likely to be associated with PCS after a single concussion $(p<0.0001)$.

\section{Discussion}

Multiple factors contribute to the risk of developing PCS from concussion, and a better understanding of these interactions is important when developing strategies to aid in prevention. The present study assessed the features of PCS cases collected from clinical charts and a prospective biomarker study, and then analyzed interactions between age, gender, concussion history and mechanism of injury. There were significant two-way associations with age, gender and mechanism of injury in our analysis. Women and older patients with PCS were more likely to have been injured in a fall or MVC compared with men and younger patients with PCS, who were more likely to have been injured in sport. In our log-linear analysis, interactions between age, gender and concussion history were conditionally dependent on mechanism of injury, but unrelated to one another. Again, women and older patients with PCS were more likely to have been injured in a fall or MVC compared with men and younger patients with PCS, who were more likely to have been injured in sport. Furthermore, our sample included more patients with PCS after a single concussion when the mechanism of injury was an MVC, whereas there were more patients with PCS after multiple concussions when the mechanism of injury was sport. Finally, there were more women who had PCS after a single concussion, compared with men, who were more likely to have PCS after sustaining multiple concussions. Our results indicate that specific patient demographics in PCS patients are associated with different mechanisms of injury, which may help predict those who could be at risk. As PCS is a growing concern worldwide, because it is associated with tremendous psychological, physical and financial burden, targeted prevention strategies should be envisioned.

There is increasing evidence that women are vulnerable to concussion. Among adult athletes, women have been reported to show an increased number and severity of symptoms after concussion. ${ }^{10}$ Women seem to be at higher risk for persistent symptoms, leading to the development of PCS, ${ }^{17,29}$ have a greater number of symptoms and are more likely to develop PCS after a single concussive event. ${ }^{4}$ This may indicate that women are more susceptible to concussions and consequently PCS than men. However, this may also suggest that women are more proactive in their health care and are therefore more likely to seek consultation after concussion compared with men. ${ }^{30,31}$ Interestingly, gender differences in PCS symptoms are not apparent in pediatric athletes, and only begin to appear in young adulthood. ${ }^{29}$

Additionally, our study has shown that there is a greater relative frequency of women with PCS following mTBI from either a fall or assault. One reason for the higher prevalence of women with PCS after a fall is owing to the increased number of falls in women, putting them at a greater risk of PCS from falls compared with men. ${ }^{31}$ Women are also at greater risk of mTBI from assault, which puts them at a higher risk for developing PCS. ${ }^{21,22}$ An issue with current data is the underrepresentation of concussion from intimate partner abuse owing to the lack of reporting from abuse and the lack of recognition of persistent concussive symptoms in women who have been subjected to intimate partner abuse. ${ }^{21}$ This clearly necessitates greater education and awareness, which can aid in the reporting and identification of intimate partner abuse.

Our study also revealed that more women than men and more older than younger people had PCS after an MVC. A previous study has shown that recovery rates from concussion were prolonged after MVC compared with sport, and there was greater symptom severity. ${ }^{32}$ The cause of greater PCS in women from MVC is unknown as men are more often involved in MVC than women. ${ }^{33,34}$ It may be that injuries in men from MVC are more serious than concussion ${ }^{33,34}$ or that in MVC, like sport, women seem to be at an elevated risk of developing post-concussion symptoms and PCS. It is not surprising that more elderly participants have PCS from MVC as statistics show that people aged 70 or older have a higher accident rate per kilometer driven than any other age group, except young male drivers. ${ }^{35}$ It is well recognized that there are age-related changes in cognitive functioning and as driving involves integration of visual, cognitive and psychomotor skills, cognitive decline can increase the risk of MVC, and consequently concussions. ${ }^{36,37}$ Our results are in keeping with those from Cassidy et $\mathrm{al}^{28}$ whereby they reported that a majority of MVC-induced mTBI occurred in females suffering an MVC and that there was delayed recovery of MVC-induced mTBI symptoms in those older than 50 .

In addition, many MVC cases in our study had PCS after a single concussive event versus those who had PCS from sport. This may be owing to the higher impact of an MVC-induced mTBI compared with the impact of a sport-induced mTBI. Additionally, this may be because many of our PCS cases with a sport-induced injury had a history of multiple injuries, and therefore they were less likely to be represented among those categorized as having had a single concussion. Finally, it may be that MVCs are more likely to be reported, and those sustaining a sport-related injury are under greater pressure to continue competing. ${ }^{38}$

Similar to others, we found that PCS from falls was more common in the elderly. ${ }^{12,17,39}$ Previous studies have also suggested that there is an increased risk of falls, and subsequently mTBI owing to cognitive impairment in the elderly. ${ }^{40,41}$ Persistent symptoms have also been attributed to less cognitive reserve in the elderly. ${ }^{41}$ In a recent mTBI study, age-related differences were observed in functional MRI activation in the frontal and parietal brain regions, while performing a working memory task. ${ }^{27}$ Younger participants showed hyper-activation of cortical regions while performing a working memory task, which resolved at follow-up. However, elderly patients showed hypo-activation following injury and did not show any improvement at follow-up. 
Only the younger patients showed a reduction in PCS symptoms. It is possible that age-related reduction in neuroplasticity/compensation prevents a return to normal neural activity in the elderly. One caveat to their study was the short follow-up time (6-weeks) following the baseline assessment, which may have been inadequate to show recovery in the elderly. Alternatively, it is possible that older adults endorse a greater number of co-morbidities, and therefore symptoms appeared to have persisted for a greater duration of time. ${ }^{42}$ Some studies have also shown increased mortality after mTBI in the elderly, even after correcting for age, education and a diagnosis of dementia. ${ }^{23}$

Our study does not come without limitations. One limitation of our study was the relatively small number of older patients. This may be owing to older people having more severe consequences from a head injury and thus more likely to suffer contusion, bleed or death. Additionally, the study required patients to recall when they had the concussion or the mechanism of injury, which may have been difficult with older patients having a cognitive impairment. However, even with memory impairment, patients can usually recall the mechanism of injury; thus, only those with severe dementia would be excluded. Another explanation for our small sample size may be owing to our exclusion criteria, which removed any patient who had a co-morbid neurological/psychological disorder because of the symptom overlap with PCS. However, we have excluded these participants as it is currently debated whether overlapping pre- and post-injury psychiatric illnessess enable an accurate diagnosis of PCS. Therefore, removal of these participants has increased the accuracy with which a patient could be diagnosed with PCS. A second limitation is that the subjects came from two sources: a prospective study of PCS patients at the Canadian Concussion Center and patients from a Concussion Clinic. This approach was used to increase the overall sample size, but this limited the number of variables and statistical tests that could be implemented. Furthermore, as DSM-IV criteria require neuropsychological assessment, we have not conducted any validity testing and it is possible that a patient may have not been motivated during the test and may have put insufficient effort in answering the questions. Finally, a lack of control group who experienced concussion without developing PCS precludes us from calculating the true risk of developing PCS in the context of different mechanisms of injury. Therefore, future work should try to gather data on all patients presenting to ER and/or family doctor to see which mechanisms of injury are associated with the highest risk of developing PCS and how this differs according to the various demographic factors.

\section{CONCLUSION}

In summary, both age and gender have unique interactions with mechanisms of injury in those with PCS. These results suggest that targeted prevention strategies for concussion injuries are warranted as different mechanisms of injury seem to be associated with a greater risk of PCS in different populations. These persisting post-concussive symptoms are associated with emotional/ psychological distress, loss of productivity and financial hardships, highlighting the importance of prevention strategies. ${ }^{43}$ Research into tailoring prevention programs to specific population, such as prevention of sport-related concussions in schools, may help reduce the risk of concussion and subsequent PCS.

\section{ACKNOWLEDGMENTS}

The authors thank all the participants for their contribution to our study.

\section{FUNDING}

The Toronto Western and General Hospital Foundation and Ontario Brain Institute provided funding for the study.

\section{Disclosure}

BV, GT, AT, RW, CT and MCT have no conflicts of interest to declare.

\section{REFERENCES}

1. McCrory $\mathrm{P}$, Feddermann-Demont $\mathrm{N}$, Dvořák $\mathrm{J}$, et al. What is the definition of sports-related concussion: a systematic review. Br J Sports Med. 2017;51(11):877-87.

2. Cassidy JD, Carroll LJ, Peloso PM, et al. Incidence, risk factors and prevention of mild traumatic brain injury: results of the WHO Collaborating Centre Task Force on Mild Traumatic. Brain Injury. J Rehabil Med. 2004:(43 Suppl):28-60.

3. Hiploylee C, Dufort PA, Davis HS, et al. Longitudinal study of postconcussion syndrome: not everyone recovers. J Neurotrauma. 2016;34(8):1511-23.

4. Tator CH, Davis HS, Dufort PA, et al. Postconcussion syndrome: demographics and predictors in 221 patients. J Neurosurg. 2016;125(5):1206-16.

5. Tator $\mathrm{CH}$, Davis $\mathrm{H}$. The postconcussion syndrome in sports and recreation: clinical features and demography in 138 athletes. Neurosurgery. 2014;75(Suppl 4):S106-12.

6. McCrea M, Guskiewicz K, Randolph C, et al. Incidence, clinical course, and predictors of prolonged recovery time following sport-related concussion in high school and college athletes. J Int Neuropsychol Soc. 2013;19(1):22-33.

7. Association AP, Association AP. Diagnostic and statistical manual of mental disorders (DSM). Washington, DC: American Psychiatric Association; 1994. pp. 143-147.

8. Association AP. Diagnostic and statistical manual of mental disorders DSM-IV-TR fourth edition (text revision). Washington, DC: American Psychiatric Association; 2000.

9. McCrory P, Meeuwisse WH, Aubry M, et al. Consensus statement on concussion in sport: the 4th International Conference on Concussion in Sport, Zurich, November 2012. J Athl Train. 2013;48 (4):554-75.

10. Broshek DK, Kaushik T, Freeman JR, Erlanger D, Webbe F, Barth JT. Sex differences in outcome following sports-related concussion. J Neurosurg. 2005;102(5):856-63.

11. Brown DA, Elsass JA, Miller AJ, Reed LE, Reneker JC. Differences in symptom reporting between males and females at baseline and after a sports-related concussion: a systematic review and metaanalysis. Sports Med (Auckland, NZ). 2015;45(7):1027-40.

12. King N. Permanent post concussion symptoms after mild head injury: a systematic review of age and gender factors. Neurorehabilitation. 2014;34(4):741-8.

13. Iverson GL, Wojtowicz M, Brooks BL, et al. High school athletes with ADHD and learning difficulties have a greater lifetime concussion history. J Atten Disord. 2016:1087054716657410.

14. Nelson LD, Guskiewicz KM, Marshall SW, et al. Multiple self-reported concussions are more prevalent in athletes with ADHD and learning disability. Clin J Sport Med. 2016;26(2):120-7.

15. Ponsford J, Cameron P, Fitzgerald M, Grant M, Mikocka-Walus A, Schönberger M. Predictors of postconcussive symptoms 3 months after mild traumatic brain injury. Neuropsychology. 2012;26 (3):304-13.

16. Dick R. Is there a gender difference in concussion incidence and outcomes? Br J Sports Med. 2009;43(Suppl 1):i46-50.

17. King NS. A systematic review of age and gender factors in prolonged post-concussion symptoms after mild head injury. Brain Injury. 2014;28(13-14):1639-545. 
18. Black AM, Sergio LE, Macpherson AK. The epidemiology of concussions: number and nature of concussions and time to recovery among female and male Canadian varsity athletes 2008 to 2011 . Clin J Sport Med. 2017;27(1):52-6.

19. Brook EM, Luo X, Curry EJ, Matzkin EG. A heads up on concussions: are there sex-related differences? Phys Sports Med. 2016;44(1):20-8.

20. Bock S, Grim R, Barron TF, et al. Factors associated with delayed recovery in athletes with concussion treated at a pediatric neurology concussion clinic. Childs Nerv Syst. 2015;31 (11):2111-6.

21. Valera E, Kucyi A. Brain injury in women experiencing intimate partner-violence: neural mechanistic evidence of an "invisible" trauma. Brain Imaging Behav. 2016;11(6):1664-77.

22. Valera EM, Berenbaum H. Brain injury in battered women. J Consult Clin Psychol. 2003;71(4):797-804.

23. Cheng PL, Lin HY, Lee YK, Hsu CY, Lee CC, Su YC. Higher mortality rates among the elderly with mild traumatic brain injury: a nationwide cohort study. Scand J Trauma Resusc Emerg Med. 2014;22:7.

24. Team RC. A language and environment for statistical computing. $\mathrm{R}$ Foundation for Statistical Computing Department of Agronomy, Faculty of Agriculture of the University of the Free State. Vienna, Austria; 2017. Available at: www.R-project org.

25. Bakhos LL, Lockhart GR, Myers R, Linakis JG. Emergency department visits for concussion in young child athletes. Pediatrics. 2010;126(3):e550-6.

26. Marshall S, Bayley M, McCullagh S, et al. Updated clinical practice guidelines for concussion/mild traumatic brain injury and persistent symptoms. Brain Injury. 2015;29(6):688-700.

27. Chen DY, Hsu HL, Kuo YS, et al. Effect of age on working memory performance and cerebral activation after mild traumatic brain injury: a functional MR imaging study. Radiology. 2016;278 (3):854-62.

28. Cassidy JD, Boyle E, Carroll LJ. Population-based, inception cohort study of the incidence, course, and prognosis of mild traumatic brain injury after motor vehicle collisions. Arch Phys Med Rehabil. 2014;95(3 Suppl):S278-85.

29. Preiss-Farzanegan SJ, Chapman B, Wong TM, Wu J, Bazarian JJ. The relationship between gender and postconcussion symptoms after sport-related mild traumatic brain injury. PM R. 2009;1 (3):245-53.
30. Wang Y, Hunt K, Nazareth I, Freemantle N, Petersen I. Do men consult less than women? An analysis of routinely collected UK general practice data. BMJ Open. 2013;3(8):e003320.

31. Stevens JA, Sogolow ED. Gender differences for non-fatal unintentional fall related injuries among older adults. Inj Pre. 2005;11 (2):115-9.

32. Seiger A, Goldwater E, Deibert E. Does mechanism of injury play a role in recovery from concussion? J Head Trauma Rehabil. 2015;30(3):E52-6.

33. Ramage-Morin PL. Motor vehicle accident deaths, 1979 to 2004. Health Rep. 2008;19(3):45.

34. Vehicle RSaM, Regulation TC. Road Safety in Canada. 2011 [cited 2017 March 16, 2017]. Available at: https://www.tc.gc.ca/eng/ motorvehiclesafety/tp-tp15145-1201.htm\#s35.

35. Li G, Braver ER, Chen L-H. Fragility versus excessive crash involvement as determinants of high death rates per vehicle-mile of travel among older drivers. Accid Anal Prev. 2003;35(2):227-35.

36. Burke SN, Barnes CA. Neural plasticity in the ageing brain. Nat Rev Neurosci. 2006;7(1):30-40.

37. Stutts JC, Stewart JR, Martell C. Cognitive test performance and crash risk in an older driver population. Accid Anal Prev. 1998;30 (3):337-46.

38. Kroshus E, Garnett B, Hawrilenko M, Baugh CM, Calzo JP. Concussion under-reporting and pressure from coaches, teammates, fans, and parents. Soc Sci Med. 2015;134:66-75.

39. Faul M, Xu L, Wald M, Coronado V, Dellinger AM. Traumatic brain injury in the United States: national estimates of prevalence and incidence, 2002-2006. Inj Prev. 2010; 16(Suppl 1):A268-A.

40. Camicioli R, Majumdar SR. Relationship between mild cognitive impairment and falls in older people with and without Parkinson's disease: 1-year prospective cohort study. Gait Posture. 2010;32 (1):87-91.

41. Rapoport MJ, Feinstein A. Age and functioning after mild traumatic brain injury: the acute picture. Brain Injury. 2001;15(10):857-64.

42. Anderson G, Horvath J, Anderson C. Chronic conditions. Making the Case for Ongoing Care. Baltimore, MD: Partnership for Solutions; [2002] 2004.

43. Gilworth G, Eyres S, Carey A, Bhakta B, Tennant A. Working with a brain injury: personal experiences of returning to work following a mild or moderate brain injury. J Rehabil Med. 2008;40(5):334-9. 